\title{
Mechanistic Impact of Oxime Formation Accompanying 1,3-Dipolar Cycloadditions of Nitrile Oxides
}

\author{
Janusz Baran and Herbert Mayr* \\ Institut für Chemie, Medizinische Universität zu Lübeck, Ratzeburger Allee 160, D-2400 Lübeck, FRG
}

Received January 25, 1989

\begin{abstract}
Benzonitrile oxide (1a) reacts with 1,1,2,2,3,3-hexamethyl-4,5-bis(methylene)cyclopentane (5) to give a mixture of the 1,3-dipolar cycloaddition product 8 and the oxime 9. This reaction is 26 times slower than the corresponding reaction of 1a with 1,2-bis(methylene)cyclopentane (15), which exclusively yields the 2 -isoxazoline 19 . With the assumption that the oxime 9 is generated by a stepwise process, one can estimate that the barrier for the concerted cycloaddition of $1 \mathrm{a}$ with 15 is approximately $2 \mathrm{kcal} / \mathrm{mol}$ lower than the barrier for the formation of an intermediate.
\end{abstract}

\section{A. Introduction}

Grünanger's observation ${ }^{1}$ that nitrile oxides 1 and arylacetylenes 2 yield the oximes 4 in addition to the normal $[3+2]$ cycloadducts 3 has played an important role in the discussion on the mechanism of 1,3-dipolar cycloadditions. ${ }^{2}$ While a common intermediate for the formation of 3 and 4 has initially been considered, ${ }^{3}$ different pathways for the formation of 3 and 4 have later been suggested ${ }^{4}$ (Scheme I).

Examples for the formation of oximes in reactions of nitrile oxides with CC double-bonded dipolarophiles are very rare. Benzonitrile oxide and furan gave $1 \%$ of an oxime in addition to the regular cycloadducts, ${ }^{5}$ and only in reactions of trifluoroacetonitrile oxide with conjugated olefins, such as styrenes, indenes, and 1,3-dienes, were larger amounts of oximes produced. ${ }^{6}$ The latter reaction was interpreted in terms of a competition between a concerted cycloaddition and a two-step substitution through electrophilic attack of the nitrile oxide (Scheme II).

Since the generation of intermediate diradicals or zwitterions from nitrile oxides and dipolarophiles appears to be feasible in view of these results, we have attempted to obtain further knowledge on these intermediates by employing 1,1,2,2,3,3-hexamethyl-4,5-bis(methylene)cyclopentane (5) ${ }^{7}$ as a mechanistic probe. As the diene 5 has previously been shown to possess increased 1,4- and reduced 1,2-reactivity, ${ }^{8}$ we had speculated that the intermediacy of $7 \mathbf{a} \leftrightarrow \mathbf{7 b}$ might give rise to the formation of the $[4+3]$ cycloadduct 6 (Scheme III).

\section{B. Results and Discussion}

1. Products from Benzonitrile Oxide and Diene 5. When benzonitrile oxide (1a) was generated from benzo-

(1) Morrocchi, S.; Ricca, A.; Zanarotti, A.; Bianchi, G.; Gandolfi, R.; Grünanger, P. Tetrahedron Lett. 1969, 3229.

(2) (a) Huisgen, R. J. Org. Chem. 1976, 41, 403. (b) Firestone, R. A Tetrahedron 1977, 33, 3009. (c) Battaglia, A.; Dondoni, A.; Mangini, A. J. Chem. Soc. B 1971, 554.

(3) Beltrame, P.; Sartirana, P.; Vintani, C. J. Chem. Soc. B 1971, 814.

(4) (a) Dondoni, A.; Barbaro, G. J. Chem. Soc., Perkin Trans. 21974 1591. (b) Bast, K.; Christl, M.; Huisgen, R.; Mack, W.; Sustmann, R. Chem. Ber. 1973, $106,3258$.

(5) Caramella, P.; Cellerino, G.; Corsico Coda, A.; Gamba Invernizzi, A.; Grünanger, P.; Houk, K. N.; Marinone Albini, F. J. Org. Chem. 1976, 41,3349 .

(6) Tanaka, K.; Masuda, H.; Mitsuhashi, K. Bull. Chem. Soc. Jpn. $1985,58,2061$

(7) Baran, J.; Klein, H.; Schade, C.; Will, E.; Koschinsky, R.; Bäuml, E.; Mayr, H. Tetrahedron 1988, 44, 2181.

(8) (a) Mayr, H.; Heigl, U. W. Angew. Chem. 1985, 97, 567; Angew. Chem., Int. Ed. Engl. 1985, 24, 579, (b) Baran, J. Mayr, H. J. Am. Chem Soc. 1987, 109, 6519. (c) Mayr, H.; Heigl, U. W. J. Chem. Soc., Chem. Commun. 1987, 1804.
Scheme I

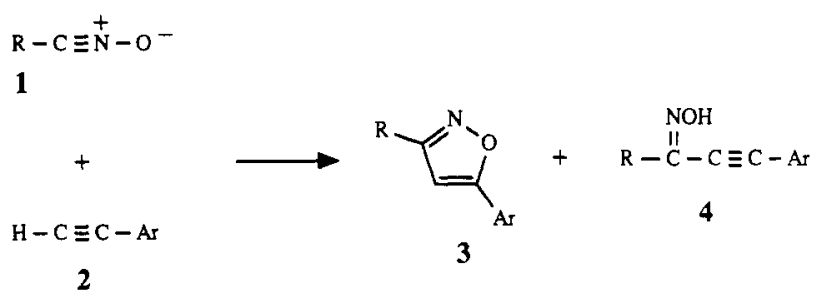

Scheme II

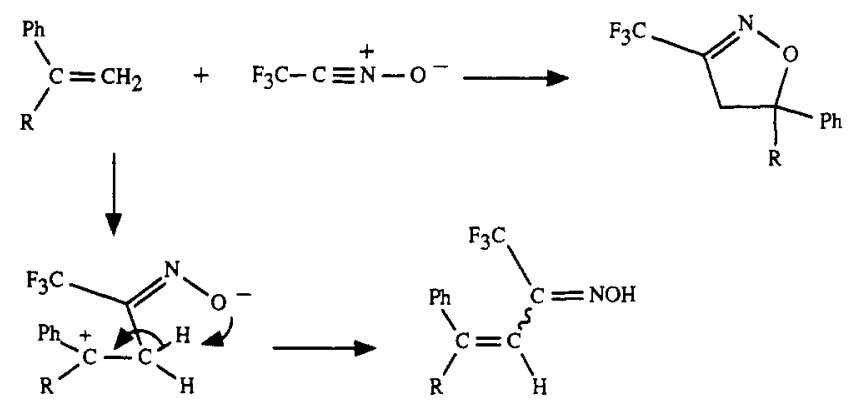

Scheme III

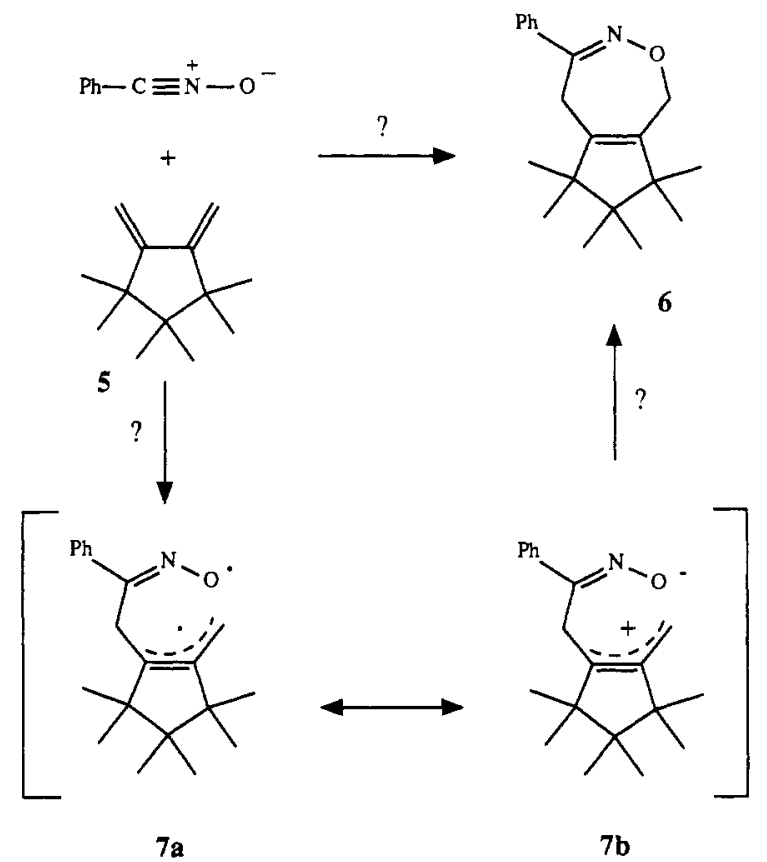

hydroxamoyl chloride and triethylamine in diethyl ether in presence of the diene 5 , the $[3+2]$ cycloadduct $8(55 \%)$ was formed concomitantly with the oxime $9(7 \%)$, the 
Scheme IV

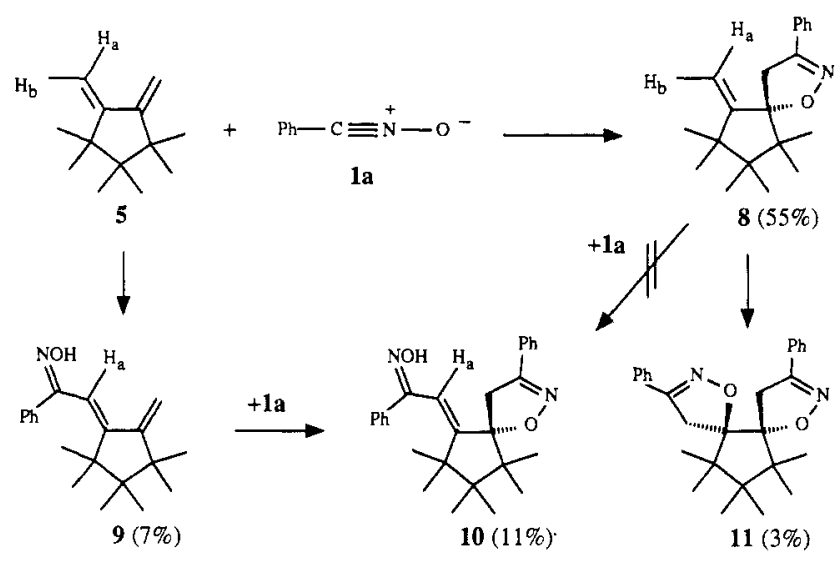

bisadducts $10(11 \%)$ and $11(3 \%)$, and 3,4-diphenylfuroxan, the dimer of $1 \mathbf{a}^{9}$ Evidence for the formation of the cycloadduct 6 and of the stereoisomers of 10 and 11 has not been found.

The $Z$ configuration at the trisubstituted $\mathrm{CC}$ double bond of 9 is indicated by the fact that the vinylic proton $\mathrm{H}_{\mathrm{a}}$ experiences a similar shielding from $9(\delta 6.43)$ to $10(\delta$ $6.09)$ as from $5(\delta 5.30)$ to 8 ( $\delta 5.04$ or 5.07). If 9 and 10 had the opposite configuration at the double bond, the vinylic proton should experience a downfield shift of approximately $0.3 \mathrm{ppm}$ as observed for $\mathrm{H}_{\mathrm{b}}$ from $5(\delta 4.75)$ to $8(\delta 5.04$ or 5.07$)$. The bisadduct 11 shows three methyl carbons in the ${ }^{13} \mathrm{C}$ NMR spectrum, indicating $C_{2}$ symmetry since for the stereoisomer with $\mathrm{C}_{8}$ symmetry, four signals would be expected. An accidental coincidence of two carbon signals in the stereoisomer of 11 is improbable, since all six methyl signals of 8 are separated from each other by at least $0.7 \mathrm{ppm}$.

Both 8 and 9 were treated with benzonitrile oxide (1a) under the original reaction conditions in order to ascertain that 10 is a sequential product of 9 , not of 8 . While 9 reacted with $1 \mathrm{a}$ instantaneously to give 10 , the reaction of 8 with 1a gave a low yield of 11 as well as the dimer of 1 .

The isoxazoline 8 is not affected when treated with triethylamine in hexane $\left(10 \mathrm{~h}, 25^{\circ} \mathrm{C}\right)$ or trifluoroacetic acid in acetonitrile $\left(10 \mathrm{~h}, 25^{\circ} \mathrm{C}\right)$. No change in the NMR spectrum was observed when neat 8 was heated at $70^{\circ} \mathrm{C}$ for $12 \mathrm{~h}$ or when a solution of 8 in toluene was heated at $98^{\circ} \mathrm{C}$ for $13 \mathrm{~h}$.

2. Reaction Mechanism. Though the expected $[4+$ 3] cycloaddition of $1 \mathbf{a}$ with $\mathbf{5}$ did not take place, another unusual reaction was observed. Compounds 9 and 10 are the first oximes that have been produced from benzonitrile oxide (1a) and a nonaromatic CC double-bonded dipolarophile. Therefore, this reaction system appeared to be suited for acquiring more information on the mechanistic significance of oxime formation accompanying the 1,3dipolar cycloadditions of nitrile oxides.

Influence of Solvent Polarity. In reactions of nitrile oxides with arylacetylenes, the oxime/isoxazole ratio was only slightly affected by a variation of solvent polarity, and the formation of oximes through zwitterionic intermediates has been excluded.,4a The situation has been different for reactions of nitrile oxides with $\mathrm{CC}$ double-bonded dipolarophiles. Oxime formation through zwitterionic intermediates has been discussed for the reaction of benzonitrile oxide with furan ${ }^{5}$ and postulated for the reactions of tri-

(9) (a) Dondoni, A.; Mangini, A.; Ghersetti, S. Tetrahedron Lett. 1966, 4789. (b) De Sarlo, F. J. Chem. Soc., Perkin I 1974, 1951.

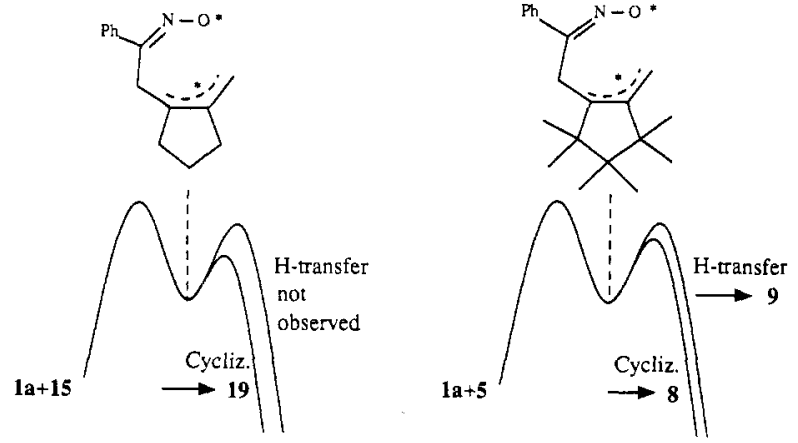

Figure 1. Energy profiles for the reactions of benzonitrile oxide (1a) with the dienes 15 and 5 with formation of a common intermediate.
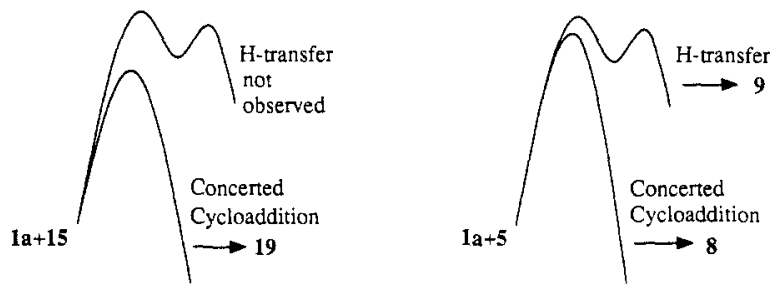

Figure 2. Energy profiles for the reaction of benzonitrile oxide (1a) with the dienes 15 and 5 assuming a concerted cycloaddition pathway.

fluoroacetonitrile oxide with conjugated olefins. ${ }^{6}$ Therefore, it appeared to be appropriate to study the influence of solvent polarity on the amount of oxime obtained from $1 \mathrm{a}$ and $\mathbf{5}$.

When $1 \mathrm{a}$ and $\mathbf{5}$ were combined in different solvents, the ratio $8 /(9+10)$ was 4.0 in hexane, 2.1 in $\mathrm{CCl}_{4}, 2.7$ in ether, and 2.1 in acetonitrile. The small amount of 11 was not quantitatively detectable under the conditions of these experiments. The lack of correlation between the isoxazoline/oxime ratio and solvent polarity excludes the possibility that 8 and 9 are generated via transition states of widely varying polarity. Therefore, 9 cannot be formed through zwitterionic intermediate $\mathbf{7 b}$ if a concerted pathway for the formation of 8 is assumed.

Comparison of 5 with Other Dienes. In accordance with previous results, ${ }^{4 b, 10}$ only the 2 -isoxazoline 16 was found when la was combined with styrene (12). Analogously, the dienes 13-15 exclusively gave [3+2] cycloadducts with 1a (Scheme V). While 14 and 15 selectively yielded the compounds 18 and 19, respectively, compound 17 , which was obtained from $1 \mathrm{a}$ and 13 , was accompanied by small amounts $(<10 \%)$ of a regioisomer. Formation of 16-19 via cyclization of initially produced oximes during workup can be excluded, since oximes have not been detected in the crude reaction products by NMR spectroscopy.

The selective formation of 19 from $1 \mathrm{a}$ and 15 indicates that the methyl groups in $\mathbf{5}$ are responsible for the formation of the oxime 9 in addition to 8 . Two possibilities to explain the different behavior of 5 and 15 are shown in Figures 1 and 2.

(a) Nitrile oxide $1 \mathrm{a}$ yields intermediates with both 5 and 15. While the intermediate formed from 19 and $\mathbf{1 5}$ undergoes exclusive cyclization with formation of 19 , the corresponding cyclization to give 8 is sterically hindered, and hydrogen transfer with formation of the oxime 9 can compete. Since 20 was found to undergo the Diels-Alder reaction with 5 even 4 times faster than with $15,{ }^{11}$ one can 
Table I. Competition Experiments for Determining Relative Reactivities of 5, 12, 13, and 15 toward Benzonitrile Oxide (1a)

\begin{tabular}{|c|c|c|c|c|}
\hline dipolarophiles (mg, mmol) & $\begin{array}{l}\mathrm{PhC}=\mathrm{NOH} \\
(\mathrm{mg} \cdot \mathrm{mmol})\end{array}$ & $\mathrm{NEt}_{3}$ (mg, $\left.\mathrm{mmol}\right)$ & product ratio (molar) & rel addtn rates ${ }^{a}$ \\
\hline $\begin{array}{l}\mathbf{5}(91.6,0.513), 13(56.4,0.521) \\
13(56.3,0.520), 12(52.6,0.505) \\
5(89.2,0.500), 12(51.9,0.498)\end{array}$ & $\begin{array}{l}14.9,0.096 \\
15.1,0.097 \\
15.8,0.102\end{array}$ & $\begin{array}{l}10.9,0.108 \\
10.9,0.108 \\
10.9,0.108\end{array}$ & $\begin{array}{l}\mathbf{8 : 1 7}=1: 4.36 \\
17: 16=1: 2.53 \\
8: 16=1: 11.7 \\
8: 16=1: 12.0\end{array}$ & $\begin{array}{l}k(5): k(13)=1: 3.49(\mathrm{NMR}) \\
k(13): k(12)=1: 2.73(\mathrm{NMR}) \\
k(5): k(12)=1: 9.89(\mathrm{NMR}) \\
k(5): k(12)=1: 10.1(\mathrm{GC})\end{array}$ \\
\hline $12(45.5,0.437), 15(41.5,0.441)$ & $13.6,0.087$ & $10.9,0.108$ & $16: 19=1: 2.63$ & $k(12): k(15)=1: 2.73(\mathrm{GC})$ \\
\hline
\end{tabular}

a Calculated according to ref 18 with the assumption that 8 and 9 are formed in 77:23 ratio (see above); the formation of the 2:1 products 10 and 11 is negligible under these conditions.

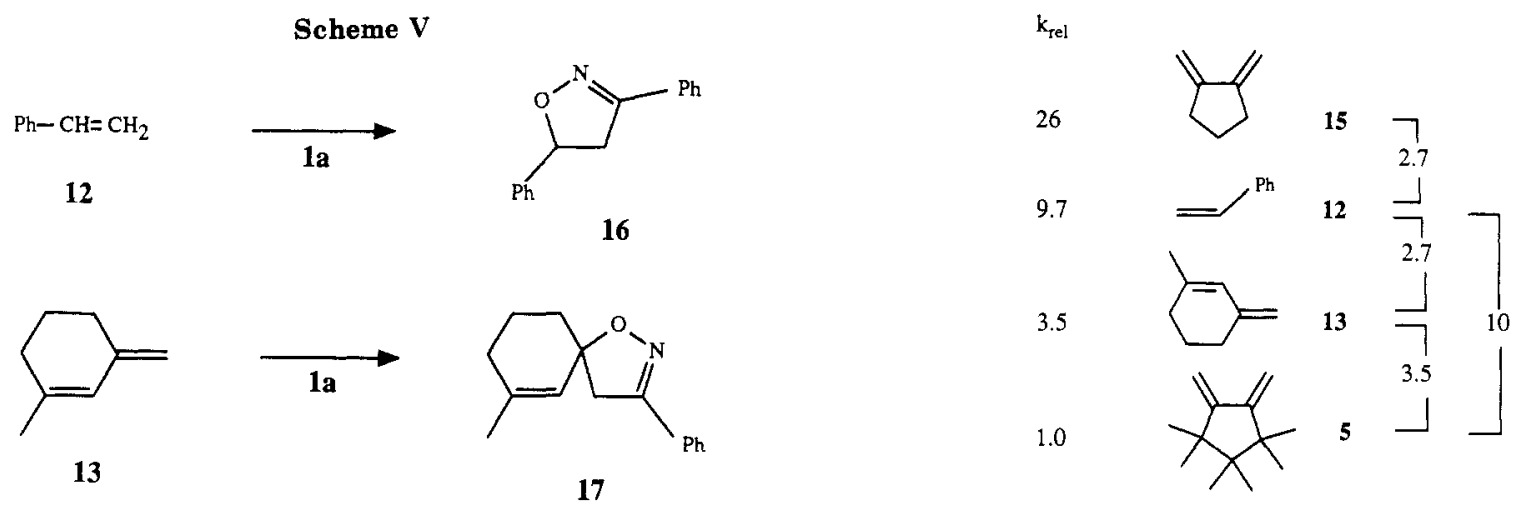

+ traces of regioisomer<smiles>C=C(C)C(=C)C</smiles>

14<smiles>C=C1CCCC1=C</smiles>

15

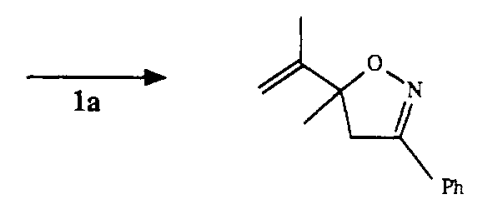

18

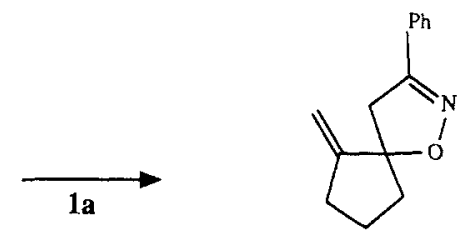

19 assume that the approach of a phenyl-substituted sp-hybridized carbon to one of the diene termini is not hindered by the methyl groups. The barrier for the formation of an intermediate from 5 can therefore be expected to be of equal height, if not lower than in the case of 15 (Figure 1).

$$
\mathrm{Ph}-\mathrm{C} \equiv \mathrm{C}-\mathrm{C}_{\mathrm{Cl}}^{\mathrm{O}}
$$

20

(b) The isoxazolines 8 and $\mathbf{1 9}$ are formed by concerted cycloadditions. Since the concerted reaction of $1 \mathrm{a}$ with 5 is retarded by steric hindrance, the formation of the oxime 9 can compete (Figure 2).

Whereas the product-determining step succeeds the rate-determining step in a (Figure 1), product determination occurs in the rate-determining step in explanation b (Figure 2). A kinetic comparison of 5 and 15 should, therefore, allow differentiation of these possibilities (Figure 3 , Table I).

(11) Baran, J.; Mayr, H. Tetrahedron 1989, 45, 3347.
Figure 3. Relative reactivities toward benzonitrile oxide (1a).

Competition experiments in $\mathrm{CCl}_{4}$ revealed that benzonitrile oxide (1a) reacts 26 times faster with 15 than with 5 , in accord with the energy profiles described in Figure 2. It should be mentioned, however, that our kinetic data do not exclude the improbable hypothesis of reversible formation of intermediates from $1 \mathrm{a}$ and $\mathbf{5}$ or $\mathbf{1 5}$ and successive rate-determining cyclization or hydrogen transfer. Though explanation b (Figure 2) offers a satisfactory explanation for the different reaction rates of $\mathbf{5}$ and $\mathbf{1 5}$ as well as for the different product composition, a blend of explanations $a$ and $b$ is also conceivable. A change of mechanism, i.e., concerted reaction of 15 and stepwise reaction of 5 , even appears to be quite attractive, since with this assumption all products obtained from $1 \mathbf{a}$ and $\mathbf{5}$ could be rationalized by the intermediacy of diradicals.

On the basis of Figure 2 (right) the barrier for the formation of the intermediate 7 can be calculated to be 0.3 $\mathrm{kcal} / \mathrm{mol}$ higher than the barrier for the concerted formation of 8 . This number is an upper limit, however, since 8 may also arise from cyclization of 7 (Figure 1, right). The small reactivity difference between 15 and 5 indicates that the reaction of $1 \mathrm{a}$ with $\mathbf{1 5}$ (which is regarded as a "normal" diene) does not profit highly from concertedness (energy of concert $^{12} \approx 2 \mathrm{kcal} / \mathrm{mol}$ ).

\section{Conclusion}

If an intermediate diradical (7) accounts for the formation of the oxime 9, closely similar activation energies for the concerted and stepwise 1,3-dipolar cycloadditions of benzonitrile oxide (1a) with 1,3-dienes can be derived. Though 7 is a reasonable intermediate to explain the formation of $\mathbf{9}$, a concerted process for oxime formation cannot rigorously be excluded, particularly since $\mathbf{6}$, an expected cyclization product of the tentative intermediate 7 could not be detected (cf. ref $8 \mathrm{~b}$ ). If a mechanism for oxime formation can be found, which avoids the inter-

(12) Doering, W. v. E.; Roth, W. R.; Breuckmann, R.; Lennartz, H.-W.; Fessner, W.-D.; Prinzbach, H. Chem. Ber. 1988, 121, 1.

(13) Houk, K. N.; Firestone, R. A.; Munchausen, L. L.; Mueller, P. H.; Arison, B. H.; Garcia, L. A. J. Am. Chem. Soc. 1985, 107, 7227. 
mediacy of 7 , the above estimates for the energy of concert of the 1,3-dipolar cycloaddition had to be augmented correspondingly.

\section{Experimental Section}

General. IR spectra were recorded on a Shimadzu IR-435 spectrometer. NMR spectra were taken on a Varian XL 200 spectrometer using tetramethylsilane as internal standard. Mass spectra were recorded on a $70-250 E$ VG spectrometer and the microanalyses were carried out by Ilse Beetz, Microanalytisches Laboratorium, D-8640 Kronach. Melting points are uncorrected. GC analyses were run on a Shimadzu GC 9A gas chromatograph equipped with FID.

Substrates. Benzonitrile oxide (1a) was generated in situ from benzohydroxamoyl chloride ${ }^{14}$ and triethylamine as described in ref $4 \mathrm{~b}$. The dipolarophiles 12 and 14 are commercially available, and 5 was prepared as described previously. ${ }^{7}$ Diene 13 has previously been prepared with a second isomer from 3-methyl2-cyclohexen-1-one and methylmagnesium iodide and successive dehydration. ${ }^{15}$ We obtained pure 13 in $56 \%$ yield from $3-$ methyl-2-cyclohexen-1-one (Aldrich), methyltriphenylphosphonium bromide, and sodium amide (Instant Ylide, Fluka) in THF following the general procedure by Schlosser. ${ }^{16}$ Bis(methylene)cyclopentane (15) was prepared in $12 \%$ overall yield from cyclopentanone by using the five-step synthesis described in ref 17 .

Benzonitrile Oxide (1a) and Diene 5. A solution of triethylamine $(3.35 \mathrm{~mL}, 2.43 \mathrm{~g}, 24 \mathrm{mmol})$ in $50 \mathrm{~mL}$ of dry ether was added dropwise at ambient temperature to a stirred solution of $5(1.68 \mathrm{~g}, 9.42 \mathrm{mmol})$ and benzohydroxamoyl chloride $(3.40 \mathrm{~g}, 21.8$ $\mathrm{mmol}$ ) in $50 \mathrm{~mL}$ of dry ether. Stirring was continued for $12 \mathrm{~h}$, and triethylammonium hydrochloride was removed by filtration and washed with a few milliliters of dry ether. The combined filtrates were concentrated under reduced pressure and finally kept at $0.01 \mathrm{mbar} / 20^{\circ} \mathrm{C}$ for $1 \mathrm{~h}$ to give $4.72 \mathrm{~g}$ of a crude product. Separation by MPLC (RP 18, $\mathrm{CH}_{3} \mathrm{OH}$ ) gave six fractions (increasing retention times): 3,4-diphenyl-1,2,5-oxadiazole 2-oxide (dimer of benzonitrile oxide) ${ }^{9}(1.04 \mathrm{~g}), 10$ (442 mg, 11.3\%), 9 (186 $\mathrm{mg}, 6.6 \%), 8(1.53 \mathrm{~g}, 54.6 \%), 11(114 \mathrm{mg}, 2.9 \%)$, and traces of nonidentified products, probably formed by attack of la at the nitrogen of the monoadducts.

6,6,7,7,8,8-Hexamethyl-9-methylene-3-phenyl-1,2-oxazaspiro[4.4]non-2-ene (8): $\mathrm{mp} 124-125^{\circ} \mathrm{C}$ (hexane); $\mathrm{IR}(\mathrm{KBr}) 2986$, $2943,2911,2866,1598,1447,1383,1376,1363,907,895,827,761$, $692,667,542 \mathrm{~cm}^{-1} ;{ }^{1} \mathrm{H}$ NMR $\left(\mathrm{CDCl}_{3}\right) \delta 0.91(\mathrm{~s}, 6 \mathrm{H}), 0.97(\mathrm{~s}, 3 \mathrm{H})$, $1.13(\mathrm{~s}, 3 \mathrm{H}), 1.14(\mathrm{~s}, 3 \mathrm{H}), 1.18(\mathrm{~s}, 3 \mathrm{H}), \mathrm{AB}$ system with $v_{\mathrm{A}}=3.22$, $\nu_{\mathrm{B}}=3.34$, and $J_{\mathrm{AB}}=17.2 \mathrm{~Hz}(2 \mathrm{H}), 5.04(\mathrm{~s}, 1 \mathrm{H}), 5.07(\mathrm{~s}, 1 \mathrm{H})$, $7.40-7.44(\mathrm{~m}, 3 \mathrm{H}), 7.70-7.75(\mathrm{~m}, 2 \mathrm{H}) ;{ }^{13} \mathrm{C} \mathrm{NMR}\left(\mathrm{CDCl}_{3}\right) \delta 18.25$ (q), 22.22 (q), 23.75 (q), 24.70 (q), 29.99 (q), $30.73(\mathrm{q}), 39.28$ (t), $44.68(\mathrm{~s}), 46.32(\mathrm{~s}), 48.07(\mathrm{~s}), 99.03(\mathrm{~s}), 107.51(\mathrm{t}), 126.44(\mathrm{~d}), 128.66$ (d), 129.75 (d), 129.97 (s), 155.74 (s), 165.24 (s); mass spectrum $(70 \mathrm{eV}), \mathrm{m} / \boldsymbol{z}$ (relative intensity) $297\left(\mathrm{M}^{+}, 44\right), 282(26), 214(28)$, 213 (42), 212 (42), 198 (31), 164 (23), 163 (27), 149 (100), 137 (38), $121(27), 110(62), 95(26), 84(49), 77(30), 69(24), 68(21), 67$ (45), 57 (21), $55(24), 43(37), 41(52)$. Anal. Calcd for $\mathrm{C}_{20} \mathrm{H}_{27} \mathrm{NO}$ (297.4): C, 80.76; H, 9.15; N, 4.71. Found: C, 80.89; H, 9.33; N, 4.95 .

$1 \cdot[2-($ Hydroxyimino $)-2-$ phenylethylidene $]-2,2,3,3,4,4-$ hexamethyl-5-methylenecyclopentane (9): $\mathrm{mp} 135-137^{\circ} \mathrm{C}$ (methanol); IR (KBr) 3209, 2977, 2944, 2909, 2870, 1491, 1473, $1456,1405,1393,1377,1367,1296,1142,1082,948,887,793,761$ $\mathrm{cm}^{-1} ;{ }^{1} \mathrm{H} \mathrm{NMR}\left(\mathrm{CDCl}_{3}\right) \delta 0.77(\mathrm{~s}, 6 \mathrm{H}), 0.92(\mathrm{~s}, 6 \mathrm{H}), 1.13(\mathrm{~s}, 6 \mathrm{H})$ $4.94(\mathrm{~s}, 1 \mathrm{H}), 5.58(\mathrm{~s}, 1 \mathrm{H}), 6.43(\mathrm{~s}, 1 \mathrm{H}), 7.34-7.38(\mathrm{~m}, 3 \mathrm{H})$, 7.65-7.70 (m, $2 \mathrm{H}) ;{ }^{13} \mathrm{C}$ NMR $\left(\mathrm{CDCl}_{3}\right) \delta 20.74(\mathrm{q}), 24.23(\mathrm{q}), 28.64$ (q), 45.10 (s), 46.73 (s), 47.58 (s), 105.03 (t), 109.51 (d), 126.94 (d), 128.31 (d), 129.32 (d), 136.45 (s), 155.64 (s), 156.70 (s), 159.71 (s);

(14) Rajagopalan, P.; Advani, B. G.; Talaty, C. N. Organic Syntheses; Baumgarten, H. F., Ed.; Wiley: New York, 1973; Collect Vol V, p 504. (15) Mironov, V. A.; Fedorovich, A. D.; Akhrem, A. A. Izv. Akad. Nauk SSSR, Ser. Khim. 1973 (7), 1570; Chem. Abstr. 1973, 79, 125928w.

(16) Schlosser, M.; Schaub, B. Chimia 1982, 36, 396

(17) van Straten, J. W.; van Norden, J. J.; van Schaik, T. A. M.; Franke, G. T.; de Wolf, W. H.; Bickelhaupt, F. Recl. Trau. Chim. PaysBas 1978, 97, 105 . mass spectrum $(70 \mathrm{eV}), m / z$ (relative intensity) $297\left(\mathrm{M}^{+}, 4\right), 296$ (8), 282 (12), 196 (11), 160 (42), 136 (20), 118 (100), 77 (17), 43 (42), 41 (14). Anal. Calcd for $\mathrm{C}_{20} \mathrm{H}_{27} \mathrm{NO}$ (297.4): $\mathrm{C}, 80.76 ; \mathrm{H}, 9.15$; $\mathrm{N}$, 4.71. Found: C, 80.56; H, 9.12; N, 5.16.

6-[2-(Hydroxyimino)-2-phenylethylidene]-7,7,8,8,9,9hexamethyl-3-phenyl-1,2-oxazaspiro[4.4]non-2-ene (10): $\mathrm{mp}$ $192-194^{\circ} \mathrm{C}$ dec (ethanol); IR (KBr) $3190,3051,2964,1592,1493$, $1479,1446,1401,1380,1373,1358,1320,1303,1147,1124,1087$, $1072,1008,992,945,920,911,879,854,827,802,780,763,754$, $692,665 \mathrm{~cm}^{-1} ;{ }^{1} \mathrm{H}$ NMR $\left(\mathrm{CDCl}_{3}\right) \delta 0.88(\mathrm{~s}, 3 \mathrm{H}), 0.91(\mathrm{~s}, 3 \mathrm{H}), 1.02$ $(\mathrm{s}, 3 \mathrm{H}), 1.04(\mathrm{~s}, 3 \mathrm{H}), 1.05(\mathrm{~s}, 3 \mathrm{H}), 1.08(\mathrm{~s}, 3 \mathrm{H}), \mathrm{AB}$ system with $\nu_{\mathrm{A}}=3.43, \nu_{\mathrm{B}}=3.53$, and $J_{\mathrm{AB}}=17.6 \mathrm{~Hz}(2 \mathrm{H}), 6.09(\mathrm{~s}, 1 \mathrm{H})$, $7.32-7.37(\mathrm{~m}, 3 \mathrm{H}), 7.40-7.45(\mathrm{~m}, 3 \mathrm{H}), 7.61-7.66(\mathrm{~m}, 2 \mathrm{H}), 7.73-7.78$ $(\mathrm{m}, 2 \mathrm{H}) ;{ }^{13} \mathrm{C} \mathrm{NMR}\left(\mathrm{CDCl}_{3}\right) \delta 19.39(\mathrm{q}), 22.04(\mathrm{q}), 23.46(\mathrm{q}), 23.93$ (q), 27.10 (q), 27.95 (q), $40.92(\mathrm{t}), 45.25(\mathrm{~s}), 47.01(\mathrm{~s}), 47.64(\mathrm{~s})$, 99.77 (s), 114.96 (d), 126.54 (d), 126.68 (d), 128.37 (d), 128.72 (d), 129.40 (d), 129.79 (s), 129.91 (d), 135.86 (s), 155.69 (s), 155.75 (s), $160.40 \mathrm{~s}$ ); mass spectrum $(70 \mathrm{eV}), \mathrm{m} / \mathrm{z}$ (relative intensity) 416 $\left(\mathrm{M}^{+}, 8\right), 399(100), 315(38), 296(37), 282(25), 230(35), 229(57)$, 212 (31), 196 (30), 188 (39), 187 (97), 186 (26), 184 (25), 146 (71), $144(31), 105$ (18), 104 (37), 103 (21), 77 (40), 41 (37). Anal. Calcd for $\mathrm{C}_{27} \mathrm{H}_{32} \mathrm{~N}_{2} \mathrm{O}_{2}(416.6)$ : C, $77.85 ; \mathrm{H}, 7.74 ; \mathrm{N}, 6.72$. Found: $\mathrm{C}$, $77.44 ; \mathrm{H}, 7.77 ; \mathrm{N}, 6.66$.

11,11,12,12,13,13-Hexamethyl-3,9-diphenyl-1,7-dioxa-2,8diazadispiro[4.0.4.3] trideca-2,8-diene (11): $\mathrm{mp} 286-287^{\circ} \mathrm{C}$ (methanol); IR (KBr) 3099, 3047, 2948, 2913, 1599, 1462, 1445, $1425,1400,1357,1258,1125,1103,1050,1021,911,860,811,758$, $690,674,664,538 \mathrm{~cm}^{-1} ;{ }^{1} \mathrm{H}$ NMR $\left(\mathrm{CDCl}_{3}\right) \delta 1.01(\mathrm{~s}, 6 \mathrm{H}), 1.06(\mathrm{~s}$, $6 \mathrm{H}), 1.14(\mathrm{~s}, 6 \mathrm{H}), \mathrm{AB}$ system with $\nu_{\mathrm{A}}=3.30, \nu_{\mathrm{B}}=3.37$, and $J_{\mathrm{AB}}$ $=18.6 \mathrm{~Hz}(4 \mathrm{H}), 7.30-7.33(\mathrm{~m}, 6 \mathrm{H}), 7.56-7.61(\mathrm{~m}, 4 \mathrm{H}) ;{ }^{13} \mathrm{C} \mathrm{NMR}$ $\left(\mathrm{CDCl}_{3}\right) \delta 22.63(\mathrm{q}), 24.23(\mathrm{q}), 25.41$ (q), $37.56(\mathrm{t}), 47.56$ (s), 48.25 (s), 102.76 (s), 126.53 (d), 128.57 (d), 129.15 (s), 129.95 (d), 156.72 (s); mass spectrum $(70 \mathrm{eV}) \mathrm{m} / \mathrm{z}$ (relative intensity) $416\left(\mathrm{M}^{+}, 6\right)$, 230 (50), 229 (89), 228 (68), 187 (71), 159 (33), 146 (46), 144 (81), $117(100), 104(28), 103(20), 84(46), 83(18), 77(35), 69(41), 67$ (12), 57 (15), $55(20), 43$ (14), 41 (41). Anal. Calcd for $\mathrm{C}_{27} \mathrm{H}_{32} \mathrm{~N}_{2} \mathrm{O}_{2}$ (416.6): C, 77.85; H, 7.74; N, 6.72. Found: C, 77.65; H, 7.81; N, 7.29 .

7-Methyl-3-phenyl-1,2-oxazaspiro[4.5]deca-2,6-diene (17) was obtained from 1-methyl-3-methylenecyclohexene $(13)^{15}(269$ $\mathrm{mg}, 2.49 \mathrm{mmol}$ ), benzohydroxamoyl chloride (109 $\mathrm{mg}, 0.701 \mathrm{mmol})$ and triethylamine ( $200 \mu \mathrm{L}, 145 \mathrm{mg}, 1.43 \mathrm{mmol}$ ) in $8 \mathrm{~mL}$ of ether, following the procedure described above. After isolation of $54 \%$ of crystalline 17, evaporation of the mother liquors afforded additional $45 \%$ of 17 , contaminated by traces of its regioisomer, which have not been purified. 17: $\mathrm{mp} \mathrm{55-56}{ }^{\circ} \mathrm{C}$ (methanol); IR (KBr) $3041,2920,2882,2857,2812,1591,1564,1495,1443,1433$, $1374,1359,1073,1004,962,954,928,905,868,850,787,753,706$, $692,676,549 \mathrm{~cm}^{-1} ;{ }^{1} \mathrm{H}$ NMR $\left(\mathrm{CDCl}_{3}\right) \delta 1.60-1.72(\mathrm{~m}, 2 \mathrm{H}), 1.75$ (br s, $3 \mathrm{H}), 1.89-2.10(\mathrm{~m}, 4 \mathrm{H}), \mathrm{AB}$ system with $\nu_{\mathrm{A}}=3.08, \nu_{\mathrm{B}}=$ 3.20 , and $J_{\mathrm{AB}}=16.6 \mathrm{~Hz}(2 \mathrm{H}), 5.51(\mathrm{br} \mathrm{s}, 1 \mathrm{H}), 7.37-7.43(\mathrm{~m}, 3$ $\mathrm{H}), 7.64-7.70(\mathrm{~m}, 2 \mathrm{H}) ;{ }^{13} \mathrm{C} \mathrm{NMR}\left(\mathrm{CDCl}_{3}\right) \delta 19.93(\mathrm{t}), 23.78(\mathrm{q})$, $29.73(\mathrm{t}), 34.59(\mathrm{t}), 46.37(\mathrm{t}), 85.14(\mathrm{~s}), 123.39(\mathrm{~d}), 126.45(\mathrm{~d}), 128.64$ (d), 129.75 (d), 130.33 (s), 141.14 (s), 156.29 (s); mass spectrum $(70 \mathrm{eV}), \mathrm{m} / \mathrm{z}$ (relative intensity) $227\left(\mathrm{M}^{+}, 41\right), 212(38), 210(20)$, 205 (16), 117 (16), 108 (100), 106 (23), 93 (59), 91 (23), 79 (24), 77 (24). Anal. Calcd for $\mathrm{C}_{15} \mathrm{H}_{17} \mathrm{NO}$ (227.3): C, 79.26; H, 7.54; $\mathrm{N}, 6.16$. Found: C, 79.59; H, 7.60; N, 6.00.

5-Methyl-5-(1-methylvinyl)-3-phenyl-2-isoxazoline (18) was obtained in $95 \%$ yield from 2,3-dimethyl-1,3-butadiene (14) (620 $\mathrm{mg}, 7.55 \mathrm{mmol})$, benzohydroxamoyl chloride $(64.7 \mathrm{mg}, 0.416$ $\mathrm{mmol})$, and triethylamine $(80 \mu \mathrm{L}, 58 \mathrm{mg}, 0.57 \mathrm{mmol})$ in $1 \mathrm{~mL}$ of dry ether: viscous oil; IR (neat 2953,1259,1087, 1016, $859 \mathrm{~cm}^{-1}$; ${ }^{1} \mathrm{H}$ NMR $\left(\mathrm{CDCl}_{3}\right) \delta 1.57(\mathrm{~s}, 3 \mathrm{H}), 1.85$ (br s, $\left.3 \mathrm{H}\right)$, AB system with $\nu_{\mathrm{A}}=3.11, \nu_{\mathrm{B}}=3.35$, and $J_{\mathrm{AB}}=16.8 \mathrm{~Hz}(2 \mathrm{H}), 4.90(\mathrm{br} \mathrm{s}, 1 \mathrm{H})$, $5.12(\mathrm{br} \mathrm{s}, 1 \mathrm{H}), 7.37-7.41(\mathrm{~m}, 3 \mathrm{H}), 7.63-7.68(\mathrm{~m}, 2 \mathrm{H}) ;{ }^{13} \mathrm{C}$ NMR $\left(\mathrm{CDCl}_{3}\right) \delta 18.73(\mathrm{q}), 25.35$ (q), $45.39(\mathrm{t}), 88.75(\mathrm{~s}), 111.02(\mathrm{t}), 126.47$ (d), 128.65 (d), 129.85 (d), 130.02 (s), 146.42 (s), 155.81 (s); mass spectrum $(70 \mathrm{eV}), m / z$ (relative intensity) $201\left(\mathrm{M}^{+}, 50\right), 186(34)$, 171 (31), 118 (63), 117 (18), 91 (19), 82 (26), 77 (60), 69 (100), 67 (54), 51 (21), 43 (56); high resolution mass spectrum, $\mathrm{m} / z$ calcd for $\mathrm{C}_{13} \mathrm{H}_{15} \mathrm{NO} 201.11536$, found 201.11518.

Benzonitrile Oxide (1a) and 1,2-Bis(methylene)cyclopentane (15). Benzohydroxamoyl chloride (106 mg, $0.681 \mathrm{mmol})$, compound $15(270 \mathrm{mg}, 2.87 \mathrm{mmol})$, and triethylamine $(120 \mu \mathrm{L}$, $87.1 \mathrm{mg}, 0.861 \mathrm{mmol}$ ) were combined in $5 \mathrm{~mL}$ of diethyl ether as 
described before to give $160 \mathrm{mg}$ of crude 19 , which was purified by MPLC (RP $18, \mathrm{CH}_{3} \mathrm{OH} / \mathrm{H}_{2} \mathrm{O}=9: 1$ ). Yield: $119 \mathrm{mg}(82 \%)$ of 19 and traces $(20 \mathrm{mg}$ ) of a bisadduct, which has not been purified.

6-Methylene-3-phenyl-1,2-oxazaspiro[4.4]non-2-ene (19): mp $42-43^{\circ} \mathrm{C}$ (pentane); IR (neat) $2946,1444,1357,915,757,690$ $\mathrm{cm}^{-1} ;{ }^{1} \mathrm{H}$ NMR $\left(\mathrm{CDCl}_{3}\right) \delta 1.63-2.72(\mathrm{~m}, 8 \mathrm{H}), \mathrm{AB}$ system with $\nu_{\mathrm{A}}$ $=3.27, \nu_{\mathrm{B}}=3.44$, and $J_{\mathrm{AB}}=17.0 \mathrm{~Hz}(2 \mathrm{H}), 5.13(\mathrm{mc}, 1 \mathrm{H}), 5.21$ (mc, $1 \mathrm{H}), 7.37-7.42(\mathrm{~m}, 3 \mathrm{H}), 7.66-7.71(\mathrm{~m}, 2 \mathrm{H}) ;{ }^{13} \mathrm{C}$ NMR $\left(\mathrm{CDCl}_{3}\right) \delta 22.12(\mathrm{t}), 31.10(\mathrm{t}), 40.01(\mathrm{t}), 45.14(\mathrm{t}), 92.78(\mathrm{~s}), 108.50$ (t), 126.52 (d), 128.66 (d), 129.86 (d), 129.98 (s), 153.43 (s), 155.91 (s); mass spectrum $(70 \mathrm{eV}), m / z$ (relative intensity) $213\left(\mathrm{M}^{+}, 36\right)$, 212 (18), 196 (8), 185 (6), 184 (8), 117 (100), 104 (9), 103 (7), 95 (9), 94 (21), $93(8), 91(11), 79(34), 77$ (34); high resolution mass spectrum, $m / z$ calcd for $\mathrm{C}_{14} \mathrm{H}_{15} \mathrm{NO} 213.11536$, found 213,11519 . Anal. Calcd for $\mathrm{C}_{14} \mathrm{H}_{15} \mathrm{NO}$ (213.3): C, 78.84; $\mathrm{H}, 7.09 ; \mathrm{N}, 6.57$. Found: C, 78.84; H, 6.95; N, 6.35.

Solvent Dependence of the Product Ratio from $1 \mathrm{a}$ and 5. The reaction was carried out with equimolar amounts of $1 \mathrm{a}$ and 5 at ambient temperature in different solvents as described for ether (see above). ${ }^{19}$ The crude product mixture was analyzed by ${ }^{1} \mathrm{H}$ NMR using the singlets at $\delta 5.04$ and 5.07 for 8 , the singlets at $\delta 5.58$ and 6.43 for 9 , and the singlet at $\delta 6.09$ for 10 . The small

(18) Ingold, C. K.; Shaw, F. R. J. Chem. Soc. 1949, 575

(19) The deviation of the $8: 9: 10$ product ratio (ether) from that reported above is due to the use of $1 \mathbf{a}$ and 5 in a $1: 1$ ratio (2:1 in the previous experiment), which reduces the probability of the sequential reaction of $1 \mathrm{a}$ with 9 to give 10 . amounts of 11 have been neglected.

\begin{tabular}{lrc} 
solvent & \multicolumn{1}{c}{$\mathbf{8 : 9 : 1 0}$} & $\mathbf{8 : ( 9 + 1 0 )}$ \\
hexane & $8: 1: 1$ & 4.0 \\
$\mathrm{CCl}_{4}$ & $5.8: 1.7: 1$ & 2.1 \\
$\mathrm{Et}_{2} \mathrm{O}$ & $10.1: 2.7: 1$ & 2.7 \\
$\mathrm{CH}_{3} \mathrm{CN}$ & $6.0: 1.8: 1$ & 2.1
\end{tabular}

Relative Reactivities of Dipolarophiles toward Benzonitrile Oxide (1a). A mixture of two dipolarophiles and benzohydroxamoyl chloride were dissolved in $4 \mathrm{~mL}$ of $\mathrm{CCl}_{4}$. Triethylamine was added, and the mixture was stirred at $20.5^{\circ} \mathrm{C}$ for $8 \mathrm{~h}$. The mixture was filtered to remove triethylammonium hydrochloride, and the filtrate was concentrated under reduced pressure to give a mixture of products, which was analyzed by ${ }^{1} \mathrm{H}$ NMR or GC.

The ${ }^{1} \mathrm{H}$ NMR analyses were based on the relative intensities of the following signals: $8, \delta 5.04$ and $5.07(2 \mathrm{~s}, 2 \mathrm{H}) ; 16, \delta 5.70$, (dd, $1 \mathrm{H}) ; 17, \delta 5.51,(\mathrm{~s}, 1 \mathrm{H})$.

The GC separation was carried out on a $50-\mathrm{m}$ SE 30 fused-silica capillary column (id $0.2 \mathrm{~mm}$ ) at $270^{\circ} \mathrm{C}$. Compounds 8,16 , and 19 had retention times of $7.66,5.87$, and $4.72 \mathrm{~min}$, respectively. For the evaluation of the product ratios, area factors of 0.5934 (8), 1.000 (16), and 0.6448 (19) were used.

Acknowledgment. We thank Mr. W. Hellebrandt for experimental assistance, Dr. E. Bäuml for discussions of the spectra, and the Deutsche Forschungsgemeinschaft and the Fonds der Chemischen Industrie for financial support.

\title{
Stepwise $[4+2]$ - and $[4+4]$-Cyclodimerizations of 1,1,2,2,3,3-Hexamethyl-4,5-bis(methylene)cyclopentane
}

\author{
Janusz Baran ${ }^{\dagger}$ and Herbert Mayr* \\ Institut für Chemie der Medizinischen Universität zu Lübeck, Ratzeburger Allee 160, D-2400 Lübeck 1, \\ Federal Republic of Germany \\ Volker Ruster and Frank-Gerrit Klärner* \\ Fakultät für Chemie der Universität, Postfach 102148, D-4630 Bochum 1, Federal Republic of Germany
}

Received March 23, 1989

\begin{abstract}
The thermal dimerization of the title compound 1 yields the $[4+2]$-cyclodimer 3 and the $[4+4]$-cyclodimer 4 in a ratio of approximately $3.5: 1$. Comparison of activation enthalpies $\left(\Delta H^{*}(3)=80.1 \mathrm{~kJ} / \mathrm{mol}, \Delta H^{*}(4)=76.6\right.$ $\mathrm{kJ} / \mathrm{mol}$ ) and activation entropies $\left(\Delta S^{*}(3)=-143.1 \mathrm{~J} / \mathrm{mol} \mathrm{K}, \Delta S^{*}(4)=-163.3 \mathrm{~J} / \mathrm{mol} \mathrm{K}\right)$ indicates both cycloadditions proceed by analogous mechanisms. A study of the pressure dependence $(0.5-9.3 \mathrm{kbar})$ yields activation volumes in the same order of magnitude for both dimerizations $\left(\Delta V_{0}{ }^{*}=-(15\right.$ to 16$\left.) \mathrm{cm}^{3} / \mathrm{mol}\right)$, indicative of two parallel stepwise processes. A selective cyclodimerization of 1 to give the $[4+2]$-cyclodimer 3 is achieved by acid catalysis.
\end{abstract}

Dimerizations of 1,3-dienes have attracted great attention in the mechanistic discussion of Diels-Alder reactions ${ }^{1}$ since the regular $[4+2]$-cyclodimers are often accompanied by certain amounts of 1,2-divinylcyclobutanes and 1,5-cyclooctadienes. ${ }^{1-3}$ The question of whether the diradical pathway, which accounts for the formation of the four- and eight-membered ring compounds, also represents the dominant route to the Diels-Alder products has been intensively studied, and evidence for concerted and stepwise Diels-Alder reactions has been presented. ${ }^{1}$ Since in most cases the studies have been carried out with acyclic dienes, the analysis of the results is complicated by the conformational freedom of the dienes.

A conformationally rigid diene fragment with sterically shielded 2- and 3-positions is incorporated in the bis(methylene)cyclopentane $10^{4}$ Since this compound has

${ }^{\dagger}$ Present address: Institute of Fundamental Chemistry, Technical University of Szczecin, Al. Piastow 42, PL-71-065 Szczecin, Poland.
Scheme I
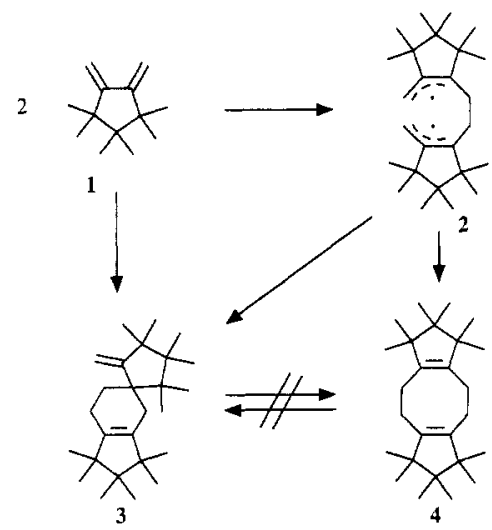

been found to give a higher amount of 1,4-adducts than other dienes in several cycloadditions, ${ }^{5}$ it appeared to be 